\title{
Mujeres casadas en los negocios y el comercio ultramarino entre el Río de la Plata y la Península a fines del siglo XVIII
}

Marcela Aguirrezabala

Universidad Nacional del Sur. Bahía Blanca (Argentina)

El presente trabajo se circunscribe al estudio de la participación económica de la mujer en un ámbito generalmente asociado a la figura masculina, como es el portuario, en la colonia y a fines del siglo XVIII. Nos acercamos a dos mujeres en particular puesto que, lejos de señalar excepciones, es a través de ellas que se puede develar su adecuación a la normativa desde dos situaciones distintas, contempladas por la legislación respecto a la mujer casada. Estas mujeres parecen conocer el lenguaje de los negocios, los vínculos mercantiles, el engranaje de una compañía comercial, las obligaciones de las partes como las contratas y valores que se manejan. Analizar las pautas de comportamiento como las estrategias utilizadas por estas mujeres en una sociedad donde los hombres son los constructores de los espacios reales e imaginarios, se nos presenta como una alternativa diferente, que nos permite dejar de lado la supuesta invisibilidad de la mujer y su identificación con el universo doméstico en función del sexo. En tal sentido, el concepto de género nos da las herramientas necesarias para estudiar a las mujeres en relación a los hombres, sabiendo que la información sobre uno es también conocimiento sobre el otro.

\section{Introducción}

La imagen de la mujer en la América latina colonial se asocia a una idea preconcebida de invisibilidad, resultante ésta de la banalización de su trabajo dentro del hogar; sin embargo, parecería insubstancial suponer que el papel jugado por la mujer, en función de lo que se esperaba de ella, hubiera estado limitado a los estrechos confines del universo doméstico. En este sentido nos resultaba interesante abordar un espacio tradicionalmente asociado a la figura masculina, como es el de la economía, específicamente en el Río de la Plata, en una época de conflictos bélicos que obligó a la península a modificar las relaciones con sus colonias a fin de otorgar fluidez al intercambio exterior rioplatense. ${ }^{1}$

1 En este campo existe una abundante bibliografía y, dada la complejidad del tema, diversas líneas de abordaje. Así, se ha incursionado en las coyunturas bélicas europeas y su incidencia en el comercio de ultramar, en el juego de intereses internacionales, nacionales y regionales, las fluctuacio- 
Dentro de ese contexto han proliferado los estudios relativos al grupo social vinculado a la economía en el Río de la Plata, tratando desde el status, composición y movilidad social al poder político y económico de los mismos; todo lo cual ha servido para comprender el papel jugado por los varones en función de la coyuntura regional, nacional e internacional. ${ }^{2}$ Esta tendencia de análisis desde los valores masculinos contribuyó al olvido de uno de los sujetos históricos, en tanto protagonistas que conciben estrategias y toman decisiones.

Sin embargo, más allá del ámbito rioplatense, Enriqueta Vila Vilar, refiriéndose a las mujeres sevillanas en el siglo XVI, manifiesta que basta un acercamiento a los fondos del Archivo de Protocolos para advertir la presencia de mujeres que intervienen en transacciones de todo tipo y refiere: "Aproximadamente un 7\% de las escrituras son generadas por ellas que aparecen en su papel de viudas o hijas requiriendo una herencia, pero también actuando en nombre del marido, ausente en Indias, como receptoras de rentas y metales, como prestamistas en pequeñas cantidades, como integrantes de compañías comerciales, como dueñas de naos, etc.”. ${ }^{3}$

nes generadas entre la legalidad y el fraude, las particularidades de las transacciones, los intereses e ideologías en pugna, la problemática de la navegación y el transporte, entre otros. Estos son sólo algunos de los aspectos que han permitido estudiar el desarrollo y desenvolvimiento de la economía rioplatense, en el área mencionada y en el transcurso de fines del siglo XVIII a principios del XIX. Ver sobre el tema los trabajos de Silva, Hernán Asdrúbal: La economía del Río de la Plata en la época de los Borbones, Buenos Aires, 1978, págs. 1-55; ídem: El comercio entre España y el Río de la Plata (1778-1810), Madrid, 1993, págs. 11-18; Fisher, J. R.: Relaciones económicas entre España y América hasta la independencia, Madrid, 1992, págs. 12-280; Martínez Shaw, C.: "El libre comercio y Cataluña: Contribución a un debate", en Comercio Libre entre España y América Latina, 1765-1824, Madrid, 1987; y Ravignani, E.: "El volumen del comercio del Río de la Plata a comienzos del Virreinato (17791781)", Boletín del Instituto de Investigaciones Históricas, tomo XV, año XI, 1952, n. 54.

2 Al respecto se pueden consultar los textos de Socolow, Susan: Los mercaderes del Buenos Aires virreinal: familia y comercio, Buenos Aires, 1991; Garavaglia, Juan Carlos: Economía, sociedad y regiones, Buenos Aires, 1987, págs. 7-65; Galmarini, Hugo R.: "Comercio y burocracia colonial. A propósito de Tomás Antonio Romero", Investigaciones y ensayos, n. 28, enero-junio 1980, págs. 407 423; Socolow, Susan: "La burguesía comerciante de Buenos Aires en el siglo XVIII", Desarrollo económico. Revista de Ciencias Sociales, n. ${ }^{\circ}$ 70, vol. 18, julio-septiembre 1978, págs. 205-216; Gelman, Daniel: "Sobre el carácter del comercio colonial y los patrones de inversión de un gran comerciante en el Río de la Plata del siglo XVIII", Boletín del Instituto de Historia Argentina y Americana "Dr. Emilio Ravignani”, Tercera Serie, núm. 1, 1989, págs. 51-69; Lugar, Catherine: "Comerciantes”, en Hoberman, Louisa, y Socolow, Susan, comp.: Ciudades y sociedades en Latinoamérica colonial, Buenos Aires, 1992, págs. 67-103; Vila Vilar, Enriqueta, y Kuethe Allan J.: Relaciones de poder y comercio colonial: nuevas perspectivas, Sevilla, 1999, págs. 25-34; Navarro Floria, Pedro, y Nicoletti, Andrea: "Formación y apertura de una oligarquía criolla en el Buenos Aires Virreinal" en Historia de los Argentinos, Premio "Coca-Cola en las Artes y las Ciencias", Buenos Aires, 1989, págs. 178-214, entre otros.

3 Ver: "Discursos leídos ante la Real Academia Sevillana de Buenas Letras el día 27 de octubre de 1996 por la Excma. Sra. Dña. Enriqueta Vila Vilar y el Excmo. Sr. D. Francisco Morales Padrón en la recepción pública del primero", Sevilla, 1997, págs. 43-67. 
Por su parte y para el siglo XVII, Lutgardo García Fuentes identifica un número superior a cuarenta mujeres exportando a Indias. ${ }^{4}$ Así, también para mediados del siglo XVII y principios del XVIII, en relación al comercio colonial en Cádiz, Carrasco González expresa: "Resulta también relevante la presencia de mujeres como acreedores de préstamos y cambios. Estas mujeres aparecerán relacionadas, algunas veces, por lazos de parentesco con mercaderes naturalizados o extranjeros. Ellas también como testaferros, pues de lo contrario sería difícil encontrar una explicación a casos como el de la viuda doña Andrea de Barces, quien prestó de una sola vez 54.440 pesos escudos ¡una fortuna! Sin embargo, hay casos en que la inversión de importantes sumas en préstamos a riesgo podía realizarse realmente en su nombre, ya que algunas de estas mujeres se hallaban respaldadas por sus propios negocios o, como ocurre con doña Alfonsa María Figueroa, por la compañía de la que era socia principal, como heredera de su marido Juan Jácome Prorrata. Otras mujeres invirtieron sus dotes, o parte de ellas, en negocios de cambios marítimos, con la esperanza de aumentar sus capitales". 5

Del mismo modo y si nos remitimos al funcionamiento de las mujeres en el Río de la Plata, no pueden desconocerse los trabajos que han apuntado a su funcionamiento en la colonia, ya sea desde el punto de vista social como desde el económico, lo que nos habla de una presencia activa sin lugar a dudas. Dentro de esa línea, se han tratado aspectos tales como la participación de las mujeres en la administración de las propiedades rurales, en el comercio al menudeo, el sector textil o el ámbito alimenticio. ${ }^{6} \mathrm{~A}$ estos estudios debemos agregar los destinados a comprender las pautas

4 En García Fuentes, Lutgardo: "Exportación y exportadores sevillanos a Indias, 1650-1700", Archivo Hispalense, vol. XL, n. ${ }^{\circ} 184,1977$, págs. 1-39.

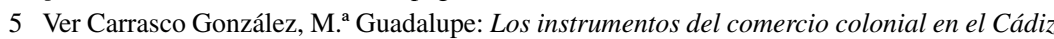
del siglo XVII (1650-1700), n. ${ }^{\circ} 35$, Madrid, 1996, págs. 110-113.

6 En cuanto a la participación de la mujer en la economía colonial, ver Borchat de Moreno, Cristiana: "La imbecilidad y el coraje. La participación femenina en la economía colonial. Quito, 1780-1830", Revista complutense de Historia de América, 17, 1991, págs. 167-181; Mallo, Silvia: "La mujer bonaerense colonial", entrevista a Silvia Mallo, en Revista de Historia Bonaerense. Instituto Histórico del Patido de Morón, n. ${ }^{\circ}$ 13, año IV, 1997; Gresores, Gabriela: "La función económica de las mujeres en la Magdalena colonial", Revista de Historia Bonaerense, Instituto Histórico del Partido de Morón, n. ${ }^{\circ}$ 13, año IV, 1997; Gellert, Alicia Mabel: "El trabajo femenino en Buenos Aires en la segunda mitad del siglo XVIII", en Knecher, Lidia, y Panaia, Marta (comp.): La mitad del país. La mujer en la sociedad Argentina, Buenos Aires, 1994; y Mayo, Carlos: "La mujer en el mundo rural", en La estancia y sociedad en el Río de la Plata (1740-1820), cap. X, págs. 165-190, Buenos Aires, 1995. 
matrimoniales seguidas por éstas o su intervención en la construcción de redes familiares. ${ }^{7}$

Así fue que descubrimos datos interesantísimos. Elena Studer señala que, en el siglo XVIII, Buenos Aires desempeñó un importante papel en cuanto al comercio negrero, cuando todavía — según ella- el tráfico no era considerado una actividad denigrante, y llegaban a esa plaza compradores desde Chile o del Alto Perú. El dato que nos llamó la atención fue la inclusión de una cantidad importante de mujeres vinculadas al tráfico negrero (31, frente a 456 varones). Otro no menos llamativo fue el caso de Vicenta Uriarte, quien aparece en un listado correspondiente a los embarcadores que extraen metálico desde Buenos Aires entre los años 1779-1783. De igual forma nos encontramos con Mercedes Bello, a quien ubicamos en el empadronamiento de los extranjeros residentes en la ciudad de Buenos Aires para el año 1807, alquilando sus habitaciones a cinco portugueses, siendo uno de ellos José Pintos, a quien se identifica como "...marinero del barco de dicha señora que se encuentra enfermo y se va a mudar al dicho barco que tiene en Las Conchas, lugar donde se pone bueno...". ${ }^{8}$

Aún así, no hemos dado con trabajos sistemáticos; se trata más bien de datos aislados, lo que es por demás elocuente para explicar por qué iniciamos esta línea de investigación. El objetivo del trabajo es, básicamente, realizar un análisis descriptivo del comportamiento de dos mujeres contemporáneas en el Río de la Plata durante el siglo XVIII, a partir de la intervención que pudieron tener en el comercio marítimo, desde la condición

7 En cuanto al tema de pautas matrimoniales y redes de parentesco conformadas por las mujeres de la colonia, ver Socolow, Susan: "Parejas bien constituidas: la elección matrimonial en la Argentina colonial, 1778-1810”, Anuario del IEHS, V, 1990, págs. 135-161; Lavrin, Asunción: Sexualidad y matrimonio en la América hispánica, Siglos XVI-XVIII, México, 1990, pág. 14; y Cicerchia, Ricardo: "Vida familiar y prácticas conyugales. Clases populares en una ciudad colonial, Buenos Aires, 1800-1810", Boletín del Instituto de Historia Argentina y Americana 'Dr. E. Ravignani", Tercera Serie, n. ${ }^{\circ}$ 2, 1990, págs. 91-109. Podríamos mencionar también los trabajos de Vergara Quiroz, Sergio: “¿Relevancia o subordinación? La mujer en la familia colonial hispanoamericana”, en Knecher y Panaia: La mitad del país...; y Rodríguez Villamil, Silvia: La historia de las mujeres en el Uruguay, Montevideo, 1991, págs. 1-21.

8 Ver cuadro XIII correspondiente al número de individuos que en las regiones del Plata se dedicaron a operaciones de compra-venta de negros, en Studer, Elena F. S. de: La trata de negros en el Río de la Plata durante el siglo XVIII, Buenos Aires, 1958, cap. XI, págs. 232 y 238. Así también el listado de "Comerciantes y embarcadores que extraen metálico desde Buenos Aires entre los años 1779-1783”, en Anexo 5 de Garavaglia, Juan Carlos: Economía, sociedad y regiones..., págs. 109-112. Respecto a la propietaria de un barco, consultar "Empadronamiento de los extranjeros residentes en la ciudad de Buenos Aires en el año 1807", Documentos para la Historia Argentina, t. XII: Territorio y Población, Buenos Aires, 1919, pág. 264. 
jurídica ${ }^{9}$ como desde las concepciones ideológicas, para percibirlas luego a través de sus movimientos en el ámbito público.

Lejos de señalar excepciones, hemos restringido nuestro estudio a dos mujeres casadas dado que, a diferencia de las solteras y las viudas, podían adecuarse a la normativa desde dos situaciones distintas contempladas por la legislación. En Ana Joaquina Silva de Melo y María del Carmen Mármol encontramos a dos mujeres involucradas en el comercio de exportación, una de ellas trabajando a la par de su esposo, D. Manuel Cipriano de Melo. La otra, esposa del Teniente de Asamblea Josef Mexia, ausente en los reinos de España, exportando por su cuenta y riesgo, o envuelta en pleitos judiciales como resultado de convenios comerciales. Estas mujeres parecen conocer el lenguaje del comercio, sus leyes, tipos de contratas, las implicancias de una compañía comercial como las obligaciones de las partes. Una de ellas utiliza las conexiones y relaciones entabladas por su cónyuge a lo largo de toda una trayectoria comercial, interviniendo así en transacciones que abarcan desde el cobro de utilidades a la compra de una fragata. La otra, a cargo de una numerosa familia, la encontramos vinculándose a la producción pecuaria y a la exportación de cueros, astas de toro, grasa y sebo. Así es que, a través del conocimiento de algunas de las áreas de ingerencia donde estas mujeres se mueven, se pretende conocer las pautas de comportamiento como las estrategias y los mecanismos utilizados en una sociedad donde los hombres eran quienes construían los espacios reales e imaginarios.

Haciendo uso alternativamente del discurso masculino y femenino, y a través de un estudio de casos 1) intentaremos responder si la presencia femenina en el comercio de exportación estuvo condicionada a la habilitación masculina y, trabajando en forma relacional los dos géneros, superando la unilateralidad de un enfoque restringido sólo al sexo femenino, lo haremos extensivo a las relaciones con el otro sexo; 2) trataremos de demostrar que el lenguaje comercial, los asuntos relacionados con el comercio marítimo y el ámbito portuario no constituyeron un espacio excluyente en función del sexo; 3) confirmaremos la utilización de estrate-

9 Entendido el concepto como "lo que ésta puede hacer dado el concepto que socialmente se tiene de su capacidad personal para realizar los actos que implican el pleno uso de sus facultades y el desarrollo de su actividad como ser de derecho". Ver Cepeda Gomez, Paloma: "La situación jurídica de la mujer en la España liberal durante el antiguo régimen y régimen liberal", en Actas de las IV Jornadas de Investigación Interdisciplinaria. Ordenamiento jurídico y realidad social de las mujeres. Siglos XVI a XX, Madrid, 1984, pág. 181. 
gias tanto por parte de la mujer como del hombre, conforme a las concepciones ideológicas aceptadas por la sociedad colonial.

En la búsqueda de un marco teórico, recurrimos al concepto de género entendido como "...la construcción de formas culturales consideradas como apropiadas para el comportamiento de individuos de sexo femenino o masculino". ${ }^{10}$ Por aludir a las relaciones sociales de los sexos, esta categoría de análisis nos induce a superar la idea de un mundo de mujeres separado del mundo de los hombres y a comprender que la información sobre las mujeres es también información sobre los hombres. Al respecto, Duby y Perrot expresan que: "Una historia de relaciones, que pone sobre el tapete la sociedad entera, que es historia de las relaciones entre los sexos y, en consecuencia, también historia de los hombres". ${ }^{11}$ Se introduce así la posibilidad de interpretar la historicidad de los roles, la naturaleza de la relación, sin dejar de lado la interacción, al mismo tiempo de conocer el camino seguido por mujeres y hombres en la construcción de sus propias identidades dentro de una realidad histórica concreta.

En cuanto a las fuentes, para este trabajo específicamente hemos tomado los Registros de Buques correspondientes al período 1793-1794, documentación esta proveniente del Archivo General de Indias (Sevilla). Asimismo, nos hemos servido de la utilización de expedientes de Tribunales y Hacienda del Archivo General de la Nación (Argentina)..$^{12}$

El manejo de fuentes editadas como los textos de Juan Apolant, que incluyen el Padrón Millán de 1726, el Censo de 1769 y el Padrón Aldecoa de 1772/1773, todos padrones básicos para el estudio de Montevideo y su jurisdicción, la obra de Félix de Azara con su relato de los Viajes por la

10 Ramos Escandón, Carmen: "El concepto de 'Género' y su utilidad para el análisis histórico", en La Aljaba. Segunda Epoca. Revista de Estudios de la Mujer, vol. 2, 1997, págs. 13-32. Cfr. Pita, Valeria Silvina: "Estudios de la mujer y estudios de género en la Argentina. Un balance pendiente", en Temas de Mujeres. Perspectiva de Género, Tucumán, 1998, págs. 703-709; Rilla, José, y Larraincí, Irma: "Historia y Mujer: La historia como lugar de lo femenino", en Rodríguez Villamil, Silvia: Mujeres e Historia en el Uruguay, Uruguay, 1992; y Rodríguez Villamil, Silvia: “¿Víctimas o heroínas? Los desafíos de las mujeres y su desarrollo en Uruguay", en Rodríguez Villamil: La Historia de las Mujeres..., entre otros.

11 Ver Duby, Georges, y Perrot, Michelle: Historia de las mujeres, El siglo XX. Guerras, entreguerra y posguerra, Madrid, 1993, págs. 7-8.

12 Archivo General de Indias, Sevilla (en adelante, AGI), Registro de Buques, Buenos Aires, legajo 580, 1793-1794. Archivo General de la Nación, Argentina (en adelante, AGN), tribunales, legajo 121, expte. 17, 1794. AGN, Sala IX, 36-6-4. AGN, IX, 41-7-6, 17 y 18 de noviembre de 1788. AGN, Sala IX, 33-4-55, Hacienda, legajo 41, expte. 11039: "Melo, Manuel Cipriano de: Segundo Comandante del Resguardo. Proceso que se le siguió por sus dobles actividades como funcionario y como particular (1788-1791)"'. 
América Meridional, los Documentos para la Historia Argentina, específicamente el tomo XII: "Territorio y Población", que contiene el padrón de la ciudad de Buenos Aires para 1778, Las Leyes de Toro, la Novísima Recopilación de las Leyes de España y el Telégrafo Mercantil, Rural, Político-Económico e Historiógrafo del Río de la Plata, junto a una importante bibliografía, sustentan el desarrollo del tema. ${ }^{13}$

\section{El caso de Ana Joaquina Silva de Melo}

Ana Joaquina Silva de Melo ${ }^{14}$ se casaba en agosto de 1765 con don Manuel Cipriano de Melo, un lisboeta con una vida bastante agitada y una amplia trayectoria en el Río de la Plata como comerciante y funcionario. ${ }^{15}$ Los conocimientos náuticos y experiencia de Melo, así como los servicios prestados al rey le valieron en 1789 el nombramiento de Teniente del Comando del Resguardo del Puerto de Montevideo, cargo que ocupó por espacio de 20 años. ${ }^{16}$

13 Ver Apolant, Juan: Génesis de la familia uruguaya, segunda edición ampliada, Montevideo, 1975, t. III, págs. 1738 y 1739. Azara, Félix: Viajes por la América meridional, tomo II, 1923, pág. 170. Documentos para la Historia Argentina, tomo XII: Territorio y Población. "Padrón de la ciudad de Buenos Aires (1778)", Buenos Aires, 1919, págs. 264 y 501. Los códigos españoles. Concordados y Anotados. Tomo Noveno. Novísima Recopilación de las Leyes de España, que contiene los Libros octavo, noveno, décimo y undécimo. Segunda edición, Madrid, 1872, t. IX, título I, ley XI y XII, págs. $305-$ 306. Leyes de Toro, LXI, pág. 579. "Telégrafo Mercantil, Rural, Político-Económico e Historiógrafo del Río de la Plata", en Colección de Libros Raros e Inéditos sobre la región del Río de la Plata, publicado bajo los auspicios de la Junta de Historia y Numismática Americana (1801-1802), tomo III, año 1802, Buenos Aires, 1914, n. ${ }^{\circ} 14$, marzo de 1802, fs. 216.

14 Había nacido en la Colonia de Montevideo, era hija del ayudante mayor Gonzalo Díaz Chávez y de doña María de Silva. Ver Sabat Pebet, J. C.: Las Bibliotecas de Don Manuel Cipriano de Melo y Doña María Clara Zabala, Montevideo, 1958, pág. 136.

15 El esposo en cuestión, siendo niño aún, había dejado su tierra natal a la muerte de sus padres; remitido a Río de Janeiro, pronto fue transferido a Colonia del Sacramento, lugar de donde se fugó para instalarse en Buenos Aires. A partir de allí intervino en la llamada guerra guaranítica, viajó a Cádiz donde se nutrió sobre cuestiones naúticas, regresó a la Colonia, luego en Buenos Aires se pondría bajo la protección de don Pedro de Cevallos, quien en las intervenciones de 1762 lo nombró práctico de su escuadra. Luego de unos cuantos viajes por el Atlántico se instaló con un comercio en la Bahía, siendo sus principales ocupaciones el tráfico a lo largo de la costa del Brasil, con Africa y con Colonia del Sacramento, aunque no por ello cesarían sus movimientos. En 1777, cuando se enfrentaron las fuerzas españolas con las portuguesas por la posesión de la Colonia, fue apresado por las fuerzas de don Pedro de Cevallos, y ante los servicios que el portugués le habría prestado durante el anterior sitio de la Colonia, decidió volver a nombrarlo como práctico de la Real Armada. Ver Bentancur, Arturo: Don Cipriano de Melo, Señor de fronteras, Montevideo, 1985, págs. 1-12.

16 AGN, IX, 36-6-4. Cfr. Bentancur: Don Cipriano de Melo..., pág. 11. 
Las relaciones de su mujer, Ana Joaquina, no parecen haber influido menos que las conexiones de las que se sirvió Melo para su nombramiento. Él había servido a la corona española, había hecho convenientes amistades como la que lo unía al masón Manuel Ignacio Fernández, intendente de la expedición de Cevallos y por supuesto con el propio Cevallos, entre otros lazos no menos promisorios. En la pintoresca descripción que el historiador Bentancur hace de la pareja, la que parece no haber quedado atrás en las conexiones era doña Ana Joaquina. Se decía que una "estrecha relación" de la mujer de Melo con un alto jefe le había propiciado a éste una vertiginosa carrera en la administración. De esta forma, el autor refiere que la persona favorecida por los encantos de la mujer de Silva, habría sido muy bien aprovechada por Melo, según uno de los serios cuestionamientos que se urdían por entonces. Urdaneta, el beneficiario de los favores de Ana Joaquina, era Contador de la Renta de Tabaco, y, según el mismo autor, don Francisco de Ortega y Monroy, quien había sido designado como Comandante de los Resguardos de todas las rentas de Montevideo y el Río de la Plata por Real Despacho de 1779, era el mismo que esgrimía tales acusaciones en los primeros tiempos del 'incorrumptible' Ortega y Monroy, bastante antes de "trabajar codo a codo" con don Cipriano y terminar presos como cómplices por sus actividades. ${ }^{17}$

La figura de Ana Joaquina no pasó desapercibida aun en uno de los tantos procesos que sufrió Melo en la investigación de los presuntos actos ilícitos que éste habría cometido siendo empleado de la Real Hacienda. Entonces el asunto pasaba por la incompatibilidad de la práctica del comercio y negocios por sí o por interpósita persona, directa o indirectamente por parte de Melo, con su referido empleo que, por su misma naturaleza, prohibía tales actividades. Al respecto y en relación a la designación de los portugueses Cipriano Melo, Manuel Cayetano Pacheco como Joaquín de Acosta Bastos, en los cargos de segundo. comandante del Resguardo de Montevideo, administrador general de los Pueblos de las Misiones y oficial en la Administración General de las Misiones, respectivamente, Tejerina señala específicamente sobre los primeros que: "A lo largo de sus extensas gestiones, tanto Melo como Pacheco hicieron del comercio con el Brasil un complemento de sus funciones en la administración colonial. Al conjugar sus actividades oficiales con otras de orden mercantil, en ocasiones lo hicieron al margen de la ley y en detrimento de los intereses del estado español. Los dos estuvieron involucrados en causas

17 Ibídem, págs. 30-31. 
por comercio ilícito, siendo fundamentalmente el primero quien usufructuó descaradamente su cargo y sus conexiones comerciales con su país de origen y con los grupos de poder peninsulares". ${ }^{18}$

No puede descartarse que el seguimiento de algunas de las operaciones realizadas por la mujer de Melo, como las compras de varias casas en la capital porteña, fueran tal vez el punto de partida de las investigaciones que hizo iniciar el virrey Loreto ${ }^{19}$ contra el funcionario del Resguardo de Montevideo. La principal imputación que recayó sobre Melo tenía que ver con la práctica del comercio de ultramar a nombre de su esposa mientras ejercía como funcionario de la Corona española. ¿Había participado su mujer de aquellas transacciones o era un agente pasivo que Melo usaba para realizar sus negocios?

Una de las evidencias era la licencia otorgada a su mujer Ana Joaquina Silva en el envío de una expedición al puerto de La Habana en 1787, asociándose al matrimonio Melo Silva con otro comerciante en dicha operación. ${ }^{20}$ La sociedad entre el comerciante y la pareja se había constituido al parecer a partir de la entrega de una casa por parte de Ana Joaquina a dicho comerciante, como pago total de la fragata "San Francisco de Asís", alias "El Tártaro". Al respecto, el imputado declaraba que: “...el Escribano Nuñez refiere en el citado certificado, de todo lo cual podrá dar noticia su mujer, que fue quien convino con la compra de la casa, como que era para ella misma y se compró

18 Al respecto y en relación a la designación de los portugueses Cipriano Melo, Manuel Cayetano Pacheco y Joaquín De Acosta Bastos, en los cargos de segundo comandante del Resguardo de Montevideo, administrador General de los Pueblos de las Misiones y Oficial en la Administración General de las Misiones respectivamente, Tejerina señala que: "A lo largo de sus extensas gestiones, tanto Melo como Pacheco hicieron del comercio con el Brasil un complemento de sus funciones en la administración colonial. Al conjugar sus actividades oficiales con otras de orden mercantil, en ocasiones lo hicieron al margen de la ley y en detrimento de los intereses del estado español. Los dos estuvieron involucrados en causas por comercio ilícito, siendo fundamentalmente el primero quien usufructuó descaradamente su cargo y sus conexiones comerciales con su país de origen y con los grupos de poder peninsulares". Tejerina, Marcela: "Portugueses al servicio de España y sus vínculos comerciales con el Brasil", en Silva, Hernán A.: Navegación y comercio rioplatense, Bahía Blanca, 1999, t. 2, págs. 163 y $135-179$.

19 Sin duda, uno de los problemas más graves que debió asumir en varias oportunidades la Corona fue el de la participación directa o indirecta de los funcionarios en prácticas fraudulentas. Tal vez el más grave enfrentamiento fue, según Silva, el que protagonizaron el Virrey Marqués de Loreto y el Superintendente General de la Real Hacienda del Virreinato, Francisco de Paula Sanz, pues "La severa actuación virreinal llevó a encausar a los más allegados colaboradores de Sanz: el Comandante de Resguardos, Francisco Ortega y Monroy y el segundo jefe, Cipriano de Melo; sin contar el grave caso contra el Administrador de la Aduana de Buenos Aires, Francisco Ximenez de Mesa...”. Silva, Hernán: "Aspectos del comercio ilícito en el Río de la Plata", Cuadernos del Sur, n. ${ }^{\circ}$ 17, 1984, págs. 70-73. Cfr. Lynch, John: Administración colonial española, Buenos Aires, 1962, cap. V, págs. 91-113.

20 Bentancur: Don Manuel Cipriano de Melo..., págs. 70-71. 
con su propio dinero...”, agregando más adelante: "como también lo son la escritura de venta que Francisco Caraballo otorgó a favor de dicha su esposa de la esquina y sitio que hoy tiene reedificada su mujer...." ${ }^{21}$

Interrogado Melo respecto a la habilitación que habría dado a su esposa para la compra de la fragata manifestaba: “...es cierto que dio permiso a su mujer para que entrase en la compra de la fragata el Tártaro..."; argumentando Melo que si había intervenido había sido consintiendo, en razón de los conocimientos que tenía sobre embarcaciones, la cual finalmente fue vendida a aquel comerciante para constituir la mentada sociedad.

En cuanto a las importantes negociaciones que, según los dichos de Melo, habría realizado Ana Joaquina Silva, tales la vinculada a la mencionada fragata, como contratas, manejo y giro de caudales, la compra y venta de varias casas, se le pedía al acusado se reconviniera sobre las mismas. A lo que el deponente contestaba que: “...desde que (su mujer ) está casada con el exponente siempre ha tenido y girado su caudal por separado, aun en el tiempo que el confesante era comerciante, y giraba con gruesas negociaciones suyas, y de comisiones, como lo tiene hecho constar ante S. M. por representaciones". ${ }^{22}$

Lo expresado en cuanto a que dichas sumas hayan sido propias de su mujer no resultaba un argumento convincente, más bien era poco creíble; de hecho, la acusación fiscal se basaba en el alegato de que no podía haber separación legítima de caudales mientras durara la unión conyugal. Si bien el causante reconocía que subsistente el matrimonio no debía haber división de caudales, sostenía haber causado pérdidas económicas a su mujer “...por lo cual estimulado de su conciencia y teniendo además de esto tres hijos fuera del matrimonio de los cuales sólo sabe de uno su mujer, de quien no tiene descendencia alguna, para evitar en lo sucesivo semejantes quebrantos y saber lo que a cada uno convenía, estipularon ambos el que cada uno girase su propio caudal, cuya razón ha consentido y se ha conformado en que su mujer gobernare el suyo en los términos que ha confesado". ${ }^{23}$ En cuanto al uso de los caudales de su mujer en su propio beneficio, el imputado se defendía alegando que si bien él los tomó en Buenos Aires “...fue con la condición de devolverse a su consorte cuando lo hubiere como pacto que precedió antes de tomárselo...”. ${ }^{24}$

\footnotetext{
21 AGN, Sala IX, 33-4-55, Hacienda, 41, 11039 (1788-1791).

22 Ibídem.

23 Ibídem.

24 Ibídem.
} 
En este pacto, que en materia económica habrían celebrado los esposos, hay otro aspecto en el que se puede advertir una aceptación tácita por parte de Ana Joaquina de la existencia de un hijo de Melo, en razón probablemente de saber que no podía darle descendencia. ${ }^{25} \mathrm{Y}$, según se desprende del discurso masculino, las implicancias de tal convenio conyugal nos permitirían pensar en una especie de "negociación" entre ambos o bien en una cierta sujeción del universo masculino respecto del femenino, con consecuencias bastante nefastas al parecer para aquél, a juzgar por los problemas en que se vio involucrado.

En el discurso de Melo la realidad era que: “...es cierto y verdadero que su mujer ha girado con su noticia y consentimiento, en esto no ha cometido delito alguno máxime teniendo su referida mujer caudal propio suyo y girado como lo ha hecho por mano de comerciantes y sujetos conocidos.... ${ }^{26} \mathrm{Al}$ respecto Betancur afirma que "...era (verdad) lo de la participación efectiva de doña Ana en cuestiones económicas...”, aunque era evidente dice el historiador, nadie podía creer en la prescindencia absoluta de Melo en dichas transacciones. ${ }^{27}$ El mismo Melo reconocía "la actividad e industria" de su esposa como la incidencia de la mujer en su ascenso económico, lo que no resultaba extraño de pensar por cuanto al morir Melo, la viuda mostraba su enojo ante la subasta de los bienes, expresando el sacrificio de tal adquisición merced a su trabajo de tantos años. ${ }^{28}$

\section{El caso de María del Carmen Mármol}

Ya lo escribía don Félix de Azara, aquel viajero que se embarcó hacia América en 1781 a bordo de un buque portugués, mientras España estaba en guerra con Inglaterra: "Las mujeres de Buenos Aires, Montevideo y Maldonado no gustan de hilar la lana ni el algodón...". ${ }^{29}$ El naturalista lo que intentaba mostrar era la ociosidad de la mujer rioplatense, proyectando de esta forma la imagen de una mujer más proclive a la pasividad, al desgano

25 Bentancur hace referencia al testamento de Cipriano de Melo en estos términos: "En 1781 dictó el primer testamento, en medio de uno de sus frecuentes achaques en buena parte consecuencias de sus desarreglos juveniles que minaron su cuerpo a través de los placeres del sexo. Dos años más tarde llevó a bautizar una hija suya, Nicolasa de los Dolores, que curiosamente anotara como 'madre desconocida'. Ver Bentancur: Don Manuel Cipriano de Melo..., pág. 27.

26 AGN, Sala IX, 33-4-55, Hacienda, 41, 11039.

27 Bentancur: Don Manuel Cipriano de Melo..., pág. 72.

28 Ibídem, pág. 131.

29 En Azara: Viajes por..., tomo II, pág. 170. 
y a indolencia que al ajetreo de las tareas. De hecho, cuando se alude a las mujeres que aparecían actuando por sí mismas, se hace referencia generalmente a las viudas; ${ }^{30}$ no obstante lo cual van emergiendo mujeres que se desenvuelven sin el aval de la figura masculina, sin mediar el estado de viudez para justificar su participación en actividades consideradas propias del hombre. ${ }^{31}$ Borchart sostiene, en relación a la participación femenina en la economía colonial quiteña para los años 1780-1830, que: "Aunque haya un buen número de transacciones llevadas a cabo por mujeres con el expreso consentimiento del padre o del marido, existen numerosas otras en las cuales las mujeres actúan solas y por su cuenta propia". ${ }^{32}$ En definitiva, como dirá Lavrin, el estado civil de la mujer no era óbice para el trabajo. ${ }^{33}$

María del Carmen Mármol era hija de Juan del Mármol, ${ }^{34}$ hacendado, propietario de una estancia en la jurisdicción de la Villa de la Concepción del Uruguay. En noviembre de 1788 encontramos a esta mujer involucrada en un litigio judicial promovido por el embargo de cueros de vaca y de toro orejanos, que le habían sido enviados por su padre desde la estancia nombrada el Rincón de Caravallo. Entonces, el alcalde de primer voto realiza-

30 Gresores, Gabriela: "La función económica de las mujeres en la Magdalena colonial", Revista de Historia Bonaerense, Instituto Histórico del Partido de Morón, n. ${ }^{\circ}$ 13, año IV, 1997, págs. 941-942.

31 Así, puede vérselas al frente de sus hogares pero también dirá Carlos Mayo que las hay propietarias de tierras, arrendando parcelas, vinculadas a la siembra y cosecha, al cuidado de animales, como a su transporte. Mayo: La estancia y sociedad..., cap. X, págs. 165-190.

32 Borchat de Moreno: "La imbecilidad y el coraje...", págs. 167-182. En relación a las mujeres que intervenían en el caso del comercio con Lima (eje Santiago-Lima) representado por el circuito Valparaíso-Callao, específicamente vinculadas a la exportación de trigo, sebo, como a la importación de algodón, vestimentas y azúcar; ver Cavieres, Eduardo: “Transformaciones económicas y sobrevivencia familiar. Elites en la transición hacia un capitalismo periférico. Chile, 1780-1840”, en Cicerchia, Ricardo, Formas familiares, procesos históricos y cambio social en América Latina, Quito, 1998, pág. 99.

33 Sobre el tema refiere: "La administración de estancias y haciendas pequeñas era menos común, pero desde el siglo XVI en adelante ésta era llevada a cabo por mujeres de todos los grupos étnicos que carecían de parientes varones. Prestar dinero en pequeñas cantidades, tejer, hacer cerámicas, coser, preparar bebidas, tales como pulque y chicha, preparar comidas para la venta en las calles o mercados y la venta de diversos productos en los mercados legales, fueron actividades desempeñadas por mujeres, principalmente de las clases bajas. En algunos centros urbanos, las mujeres administraban panaderías y trabajaban en las fábricas de cera y tabaco. El trabajo por cuenta propia gozaba de una posición más elevada que la del servicio doméstico o el trabajo en una fábrica u obraje". Ver Lavrin, Asunción: "La mujer en la sociedad colonial hispanoamericana", en Bethell, Leslie: América latina colonial: población, sociedad y cultura, Barcelona, 1990, t. 4, pág. 116.

34 En el empadronamiento realizado para la ciudad de Buenos Aires en el año 1778 hemos encontrado a una familia integrada por Juan Mármol de 50 años de edad, casado con Francisca Logrego, de 30 años de edad, de origen español y carpintero de profesión, con 8 hijos, una de las cuales se llamaba María del Carmen Mármol, entonces de 10 años de edad. Ver "Padrón de la ciudad de Buenos Aires (1778)", Documentos para la Historia Argentina..., pág. 501. Cfr. Apolant, Juan Alejandro: Génesis de la familia uruguaya, Montevideo, 1975, t. 1, pág. 769. 
ba la diligencia de reconocimiento de la producción de Mármol y constataba la presencia de 94 cueros de vaca y 9 de toro orejanos; en consecuencia, María del Carmen Mármol debía suspender la entrega de los mismos y justificar que eran bien habidos y que provenían de la estancia paterna. Dicho testimonio será certificado por los vecinos de Mármol al declarar que “...es muy cierto que (Juan del Mármol ) tiene ganados vacunos orejanos en dicha estancia, por no serle posible marcarlos todos al tiempo de la yerra a causa de que muchos ganan el monte y aunque entre los vecinos de aquel partido se observa la costumbre de señalar los terneros al pie de sus padres, hállanse orejanos interpolados con haciendas ajenas...”, manifestando otro de los vecinos que Don Juan de Mármol no era un negociante clandestino de dichos frutos. ${ }^{35}$

En 1794 María del Carmen Mármol, casada, con una gran prole a cargo ${ }^{36}$ aparecía registrada en los navíos de registro despachando su carga en 'La Prosperidad", surta en el puerto de Montevideo, próxima a regresar a Málaga con escala en Cádiz. Tal como surge de la documentación, la mujer “...embarcó por su cuenta y riesgo y a entregar en Cádiz a Don Miguel Merino y Zaldo, a Don Juan Beato Romero setecientos cuarenta y dos cueros al pelo marcados, cuyos derechos de Alcabala y ramo de Guerra sobre el valor de ocho reales cueros quedan satisfechos en la Real Aduana de Buenos Aires según guía número dos mil seiscientos sesenta y ocho, fecha veintiocho de agosto último". ${ }^{37}$

Sin duda, en el caso que nos ocupa, María del Carmen Mármol gozaba de las ventajas y desventajas de su estado civil. ${ }^{38}$ Por un lado, experimentaba la autonomía e independencia que parecían conseguirse recién con la viudez y, por otro, en su estado de casada con el Teniente de Asamblea D. Josef Mexía, “...ausente en los Reynos de España...”, debía asumir la manutención de la familia a cargo. Ello implicaba para esta mujer la nece-

35 AGN, IX, 41-7-6, 17 y 18 de noviembre de 1788.

36 AGN, tribunales, 121, 17, 1794.

37 AGI, Registro de Buques, Buenos Aires, legajo 580, 1793-1794.

38 Al respecto, creemos indispensable en un futuro cercano realizar un estudio de la condición social de la mujer, a fin de ver la incidencia tanto en las necesidades como en las posibilidades de actuación de las mujeres. Lawrence Stone sostiene para el siglo XVIII en Inglaterra que: "La subordinación de las esposas al marido se aplica con certeza a las clases alta y media alta, pero la situación es menos clara entre los artesanos, mercaderes, pequeños propietarios y trabajadores no especializados. En estas clases en cualquier período de la sociedad preindustrial, el marido, la mujer y los hijos tendían a formar una sola unidad económica, como la tripulación de un barco, en la que el papel de la mujer era básico. Cuando el marido estaba lejos, ella atendía el negocio en su lugar. "Ver Stone, Lawrence, Familia, sexo y matrimonio en Inglaterra, 1500-1800, México, 1979, pág. 114. 
sidad de relegar las tareas mujeriles, en su caso vinculándose a la producción pecuaria y al comercio de exportación.

Durante ese año de 1794, encontramos a María del Carmen Mármol presentándose esta vez ante la justicia, exponiendo los daños y perjuicios que había sufrido por el incumplimiento de una contrata para el traslado a la capital de unos 714 cueros faenados, leña, sebo y grasa de su estancia, sita en el partido conocido como Perucho Berna, en la Banda Oriental, “...bien segura yo en el antecedente concierto y perfeccionado contrato...", ${ }^{39}$ dice la señora.

Mármol expresaba que se había visto obligada a rechazar el ofrecimiento de dos lanchas "...para conducir la carga que sabían tenía yo en el puerto...", por haber consentido con éste que ahora denunciaba, a la vez que "...mediante estas seguridades espontáneamente ofrecidas de parte de Gomensoro y su patrón de Lancha no perdí instante en juntar y hacer acarrear toda mi carga.... las orillas del Puerto de Fleitas en distancia de dos leguas de mi hacienda inmediato a mi estancia...".

Entre otras cosas, Mármol señalaba que el descuido de su carga durante el tiempo que había permanecido en espera en las márgenes del río Uruguay le había significado que “...de 714 cueros que yo tenía puestos en el embarcadero...no quedaban más que 660...y para precaver su total robo me fue preciso poner tres hombres y un capataz que los custodia en sacudir y libertar de la polilla" ${ }^{40}$ A ello debía agregarse que, a causa del sol y los vientos de la zona, el cuero había perdido su grasitud, que es lo que le confiere más peso y estimación: 54 cueros de la partida acopiada se habían robado y el sebo se había derretido. En definitiva, al deterioro de su producción había de sumarse el contrato del servicio de otra persona para transportar lo que quedaba de la carga, debiendo pagar la mujer un exceso de valor considerando las pérdidas sufridas, más los costos ocasionados por la custodia y conservación de los restantes como de las otras especies acarreadas al embarcadero.

En la presentación, María del Carmen Mármol se lamentaba: "No puedo ponderar a V. S. cuantos afanos, congojas y diarias molestias me ocasionó el referido documento, la más apurada pintura de mi congojosa situación en aquel lance, desfiguraría desde luego mis verdaderos padecimientos: mi gente toda y aun yo misma, éramos pocos emisarios para aunar los deseos de proporcionar por algún medio el correspondiente buque a mis

39 AGN, tribunales, 121, 17, 1794.

40 Ibídem. 
efectos acopiados y por otra parte, todos estos mismos eran necesarios por las diarias operaciones de la hacienda". ${ }^{41}$

Por otra parte, asesorada legalmente o tal vez muy avezada en la materia, apelaba a "...los estrechos vínculos de los contratos, resorte necesario de la sociedad...", agregando "...inno es éste el arbitrio que franquea nuestra legislación cuando la prudencia y atención fueron inútiles para recuperar sus daños?, para seguir "....ंen qué pues consiste bajo estos respectos la injusticia, el exceso, la temeridad y cavilación de mi demanda?". ${ }^{2}$

A través del registro que da cuenta de la exportación de cueros con destino a Cádiz, como de su exposición ante los funcionarios, se evidencia que María del Carmen Mármol no sólo se ocupaba de las faenas cotidianas de la campaña como las organizativas y del manejo de personal a su cargo, sino que además parecía ser una entendida y conocer los valores que se cobraban por cada flete. Otro de los puntos que tocaba Mármol en su manifestación era su calidad de jefe de familia en ausencia de su esposo, recordando a quien debía juzgarla que también eran de su incumbencia las llamadas tareas mujeriles como la crianza de los niños: “...y cuando yo tenía acopiadas algunas producciones con el objeto de aumentarlas para retirarme al sosiego y tranquilidad de mi casa en este vecindario, debiendo consideración a la larga familia que me es forzoso anualmente abandonarla...". ${ }^{43}$

Finalmente la causa se substancia a favor de la demandante y se notifica a Gomensoro el resultado de la sentencia por la que fue condenado a satisfacer los perjuicios y costas estimados en la cantidad de doscientos pesos. En definitiva y tal como afirma Lavrin: "Las sociedades de la América española colonial compartieron con España la idea de la debilidad intrínseca del sexo femenino, y heredaron el sistema legal que pretendía proteger a las mujeres de su propia debilidad o del abuso de los hombres". ${ }^{44}$

\section{La actividad comercial femenina y la legislación}

Es posible que la legislación resulte medular en el proceso de reproducción social de las diferencias genéricas, al menos no puede desconocerse que es uno de los elementos que interviene en la construcción del

\footnotetext{
41 Ibídem.

42 Ibídem.

43 Ibídem.

44 Lavrin: "La mujer en la sociedad...”, pág. 114.
} 
género, por cuanto fija las normas propias o adecuadas para la mujer y el varón. Al respecto Ramos Escandón refiere que: "Si la ley es la norma, el parámetro ideológico a partir del cual se trata de ordenar y aprender la realidad, su análisis desde una perspectiva de la relación entre los géneros cobra significación puesto que en la forma en que se conceptualiza a la mujer está implícita una forma de representación, una proyección de un universo simbólico en el que la mujer queda representada como inferior y que ordena las relaciones sociales entre los sexos como relaciones desiguales de poder, en donde el lugar subordinado es asignado a la mujer". ${ }^{45}$

La codificación para la América colonial heredada de España y proveniente de las Siete Partidas (1265), el Ordenamiento de Alcalá (1386), las Ordenanzas de Castilla (1484) y las Leyes de Toro (1505), que serán recogidas por la Nueva Recopilación (1567) y por la Novísima (1805), no ha hecho más que reflejar la realidad de la mujer al ubicarla en una posición de inferioridad frente al hombre.

Las mujeres solteras vivían sometidas a la figura paternal, en su defecto la tutela era ejercida por el mayor de los hermanos varones o, llegado el caso, por el familiar más próximo. Cuando el matrimonio se avizoraba como la posibilidad para alcanzar la libertad, las mujeres no hacían más que caer en otras redes, no menos estrechas que las primeras, esto es, bajo la sujeción marital. $\mathrm{Al}$ respecto, quisimos reproducir las reflexiones de una dama porteña aparecidas en el Telégrafo Mercantil en 1802 que reflejan lo expuesto: "La buena crianza quiere que se le hable, si se le hacen preguntas se pone colorada, ó se sonríe fuera de tiempo: siempre reprimida, ya por lo que sabe, ya por lo que ignora...En la restricción, y el enojo que padece, espera impaciente que una mutación de nombre la conduzca a la independencia, y a los placeres: llega este momento deseado: sin consultar, ni la inclinación, ni la relación de los humores, en ocho días se conducirá al altar esta víctima joven, allí se le impondrá que va a unirse para siempre con un hombre, que puede ser que jamás habrá visto, que no lo puede amar, y que nunca lo amará, más ella debe sacrificarse a las conveniencias: así da su mano pensando encontrar resarcimiento en la libertad que adquirirá...". ${ }^{46}$

45 Ver Ramos Escandón, Carmen: "Legislación y representación de género en la nación mexicana: La mujer y la familia en el discurso y la ley, 1870-1890", trabajo presentado en el XII Congresso Internacional de AHILA América Latina: Outro Ocidente? Debates do final do milénio, Portugal, 21-25 de septiembre de 1999.

46 En “Telégrafo Mercantil Rural...”, t. III, págs. 205-206. 
Quedaba pues esperar el estado de viudez, la última alternativa donde la mujer podía gozar de capacidad civil. ${ }^{47}$

Es decir que en Hispanoamérica, dentro de la institución matrimonial, la figura masculina era la que legitimaba y las mujeres, dentro de ese espacio, tenían libertad de decisión o lo que era lo mismo, se convertían en "sujeto de derecho". ${ }^{48}$ Por lo tanto, las mujeres requerían el consentimiento de los cónyuges al momento de querer ejercer cualquier actividad, aunque ello no significaba la pérdida total de derecho legal y económico por parte de ésta. Según Lavrin, las mujeres pasaban del control del padre al del marido, no obstante lo cual, ello no implicaba un sometimiento total al hombre, al punto que: "Las mujeres podían mantener el control sobre los bienes adquiridos antes del matrimonio (bienes parafernales) y disponer de ellos según su voluntad. El sistema hereditario era bilateral y los hijos podían heredar tanto de la madre como del padre. De este modo, la personalidad legal y económica de las mujeres no era absorbida completamente por el matrimonio". ${ }^{49}$

Pero pese al criterio imperante de sujeción legal de la esposa con respecto al esposo, evidentemente ésta no siempre fue un agente pasivo $\mathrm{y}$, según las circunstancias, buscó ocupar espacios en defensa de sus intereses. Ana Joaquina tenía caudal propio, había girado importantes sumas, realizado contratas, comprado y vendido, para lo cual se había servido de individuos por ella conocidos en el ambiente comercial.

Es pues a través del discurso masculino que adquiere significado el papel representado por Ana Joaquina, a la que se identifica como el sujeto activo de la relación, en tanto que Melo se autopercibía como un sujeto pasivo, víctima de la participación de su mujer en los negocios, aún cuando su esposa se había movido bajo su licencia y consentimiento en función del vínculo. Ana Joaquina no había hecho más que adecuarse a la ley conforme a la cual la mujer, durante su matrimonio, no podía hacer contrato alguno, ni estar en juicio haciendo ni defendiendo sin la licencia del cón-

47 Ver Ots Capdequí, J. M.: El estado español en las Indias, Buenos Aires, México, 1941, pág. 96. También consultar Ots Capdequí, J. M.: "El sexo como circunstancia modificativa de la capacidad jurídica en la legislación de Indias", en Instituciones sociales de la América española durante el período colonial, La Plata, 1934, pág. 206. Cfr. Muriel, Josefina: Las mujeres de hispanoamérica. Epoca colonial, Madrid, 1992, págs. 313-318.

48 Expresión utilizada por Cicerchia para decir que: "Sólo desde esta condición (en matrimonio), alcanzó un poder capaz de disputar el control de la voz familiar", ver Cicerchia: Formas familiares..., pág. 108.

49 Ver Lavrin: "La mujer en la sociedad...”, pág. 114. 
yuge. ${ }^{50}$ Todo lo que podía hacer Manuel Cipriano de Melo era argumentar que él "...no tiene por delito el que su mujer lo haya ejecutado...". ${ }^{51}$

Por la Ley 56 de Toro, se disponía que el marido era quien podía dar licencia general a su mujer para contraer, y hacer todo aquello que no podía hacer sin su licencia "...y si el marido se la diere, vale todo lo que su mujer hiciere por virtud de la dicha licencia". ${ }^{52}$

Cuando en 1790 el virrey Arredondo dio por terminada la causa seguida contra don Cipriano de Melo, quien por entonces venía cumpliendo su arresto, expuso en el auto definitivo haber contemplado la buena fe esgrimida por el acusado, agregando: "...aunque mezclada de una inexcusable mala inteligencia de principios, en haber consentido a su mujer las negociaciones que resultaban del sumario". ${ }^{53}$ Las Leyes de Toro habían dado un paso más; la mujer no tendría responsabilidad alguna cuando existiera una deuda, aun cuando ella la hubiera contraído,${ }^{54}$ ni siquiera se podían confiscar los bienes de la esposa para satisfacer la deuda, y menos aún encarcelarla. ${ }^{55} \mathrm{Al}$ respecto, explica Friedman, esto hace pensar que las mujeres estaban ubicadas en la categoría de menores de edad, incapaces de participar activamente en asuntos vinculados a los negocios y finanzas. ${ }^{56}$

Por otro lado, esto es porque el sistema legal en cuanto a la situación de la mujer, derivada ésta de su condición de hija o esposa, ${ }^{57}$ estaba estructurado no sólo en base a disposiciones restrictivas sino también protectoras o tutelares al mismo tiempo, circunstancia ésta que le permitió a la mujer adecuarse según la oportunidad. ${ }^{58}$ Así pues, a pesar de que, desde la per-

50 Novísima Recopilación..., Ley 55 de Toro, t. IX, título I, ley XI, pág. 305.

51 AGN, Sala IX, 33-4-55, 41, 11039.

52 Novísima Recopilación..., t. IX, 1. X, tít. I, 1. XII, pág. 305-306.

53 Bentancur: Don Manuel Cipriano de Melo..., pág. 84.

54 "No se registran en nuestra legislación de Indias preceptos específicos que regulen de una manera amplia y sistematizada la capacidad jurídica de la mujer en la esfera del derecho de obligaciones. Se han de suponer vigentes, por tanto, los mismos principios del Derecho peninsular, con la sola salvedad de algunas normas restrictivas de la capacidad para contratar impuestas a las mujeres de determinados funcionarios públicos y otras reguladoras del contrato de arrendamiento de servicios y encaminadas a proteger a las mujeres de raza india". Ots Capdequí: "El sexo como circunstancia...", págs. 209-210.

55 Novísima Recopilación..., Leyes de Toro, 1. XI, pág. 579.

56 Friedman, Ellen: "El estatus jurídico de la mujer castellana durante el antiguo régimen", en Actas de las IV Jornadas..., págs. 41-50.

57 En estos términos se refiere Capel Martínez a la situación de la mujer en su estudio de la documentación notarial como fuente histórica; ver Capel Martínez, Rosa María: "Los protocolos notariales en la historia de la mujer en la España del antiguo régimen", en Actas de las IV Jornadas..., págs. 169-178.

58 Mariluz Urquijo, José M.: "El horizonte femenino porteño a mediados del setecientos", en Investigaciones y Ensayos, n. ${ }^{\circ}$ 36, 1987, págs. 57-91 
cepción femenina, esta concepción de la tutela del esposo sobre la esposa nos conduce irremediablemente a valorarla desde una perspectiva de sumisión y obediencia, Lavrin manifiesta que, en definitiva, "El equilibrio de las implicaciones negativas y positivas del concepto legal de protección, dio a la mujer colonial un considerable grado de libertad y autoridad". ${ }^{59}$ En el caso específico de María del Carmen Mármol, ante la ausencia de su esposo, era el juez quien, siendo necesario o provechoso a la mujer, podía darle licencia, valiendo ésta como si su esposo se la hubiera dado. ${ }^{60}$

María del Carmen Mármol se había manejado con solvencia y se había posicionado en un lugar asociado a la masculinidad; sin embargo, haciendo uso del estigma de la fragilidad inherente al género y perpetuando aquella imagen de receptora pasiva de la acción del varón, manifestaba: "...la irregular conducta del patrón Otegui o de su amo Gomensoro conmigo, me dejó acopiados en el citado puerto burlándose acaso con el ningún cumplimiento de su contrato de la poca versación de nuestro sexo en aquel tráfico". ${ }^{61}$

Paloma Cepeda Gómez refiere que "El Derecho Romano, fundamento de todo el derecho posterior español y extranjero, se basa en la 'imbecilitas sexus' de la mujer y la somete a la 'potestas' marital o del 'pater familias"'. ${ }^{62}$ No obstante, se puede advertir que mientras por un lado Mármol intentaba persuadir a la justicia, ausente la figura masculina, de su condición de imbecilidad atribuida a las féminas, de la necesidad de protección ante la situación a la que se encontraba expuesta, por otro invertía su discurso y se convertía en sujeto activo al decir: “...también se me arrogó bastante perjuicio, pues cuando en los referidos viajes que tengo hechos de mi hacienda a esta capital con iguales producciones y tal vez más cuantiosas que las referidas, he pagado siempre ciento veinte y cinco o ciento treinta de flete, regular precio de todo buque desde aquel hasta este puerto, la necesidad de salir de mis apuros y redimir principalmente los cueros de una total perdición, me hicieron acceder...en satisfacer los doscientos ochenta pesos que me costó mi regreso....". ${ }^{63}$

59 Lavrin: "La mujer en la sociedad...", pág. 114.

60 Novísima Recopilación..., Ley 59 de Toro, t. IX, 1. X, tít. I, 1. XV, pág. 306.

61 AGN, tribunales, legajo 121, 17, 1794.

62 Cepeda Gómez: "La situación jurídica de la mujer...”, pág. 181-193. De todas formas vale aclarar, como hace Arrom, que el término "imbecilitus sexus" no aparece en los textos legales españoles. Cfr. Arrom, Silvia Marina: Las mujeres de la ciudad de México, 1790-1857, México, 1988, pág. 77.

63 AGN, tribunales, 121, 17, 1794. 
Evidentemente, la mujer estaba lejos de demandar estimulada por “...el desaogo de pasiones particulares...", como dirá Gomensoro en el momento de su exposición. ${ }^{64}$ En este sentido, la incorporación del concepto de género nos ha permitido como dice Rodríguez Villamil “...develar cuál ha sido a través del tiempo la naturaleza de la relación. Cómo funciona y evoluciona a nivel de las representaciones, los saberes, los poderes y las prácticas cotidianas. En la ciudad, en el campo, en el trabajo, en la familia, en lo público y en lo privado". ${ }^{55}$ Mármol no sólo entendía el lenguaje y la práctica del comercio, sino que además sabía cómo administrar y defender sus intereses; de hecho controlaba todas las etapas de la producción.

Sin duda, las estrategias utilizadas por varones y mujeres en el ámbito público, así como los distintos mecanismos que distinguieron los roles asumidos por ambos, nos dan la pauta de la adecuación del género a una situación dada, independientemente de los comportamientos o atributos considerados propios de cada sexo, o las limitaciones ideológicas o las impuestas por la legislación. De allí la importancia como dice Sapriza de “...desplazar el interés del objeto de estudio 'mujeres' hacia los espacios de relación donde interactúan hombres y mujeres, porque es en ellos que se refuerzan los estereotipos o se resiste a ellos..." ${ }^{66}$

Hasta aquí es factible pensar que la construcción histórica de una imagen de subordinación de la mujer respecto al cónyuge perpetuó, a su vez, la imagen de un sujeto pasivo y receptor de las acciones de los demás, cuando en realidad el enfoque puede invertirse. En todo caso es importante tener en cuenta, como expresa Chambeaud, que "Las relaciones de género, en tanto relaciones de poder, pueden resolverse en términos de igualdad o como relaciones dominantes. En nuestra cultura se han configurado como relaciones de dominación del género masculino sobre el femenino". ${ }^{67}$

\section{Consideraciones finales}

Nuestro interés se ha centrado en iniciar una línea de investigación diferente en los estudios que se circunscriben a la participación femenina en el ámbito de la economía rioplatense durante el siglo XVIII. En función

64 Ibídem.

65 Ver Rodríguez Villamil: “¿Víctimas o heroínas?..., pág. 40.

66 Ver Sapriza, Graciela: "Comentario", en Mujeres e historia en el Uruguay, págs. 142-147.

67 Ver Chambeaud, Lía Rosa, 1998: "Sexo-Género en el discurso pedagógico de la formación docente”, en Temas de Mujeres..., págs. 584 a 594. 
de ello y a fin de superar el discurso feminista que no hace más que reforzar la marginalidad, o por el contrario, el histórico que niega visibilidad a las mujeres a partir de un estereotipo de receptoras pasivas de la acción de otros, recurrimos a la comprensión del intrincado procedimiento de emisión/incorporación de señales, en orden a la división genérica.

Al contraer nupcias, la mujer veía limitada su capacidad para contratar y obviamente esa limitación estaba dada por su obligación de obediencia marital, que pasaba a estar por encima de su derecho personal para la contratación. Desde esta perspectiva, a través de la legislación se adscribían espacios de poder, en tanto en cuanto el estado determinaba los derechos y responsabilidades inherentes a cada sexo, que se traducían en relaciones de dominación del género masculino sobre el femenino. Ahora, una vez otorgado el consentimiento legal del cónyuge, éste asumía la responsabilidad por su mujer ante la ley, la esposa tenía absoluta libertad para actuar, es decir se convertía en sujeto activo. De estar ausente el esposo, el juez podía habilitarla en su nombre.

Hemos visto que si bien los cónyuges funcionaban como habilitadores de espacios, la reciprocidad de beneficios y responsabilidades en la jerarquización genérica que de esto se derivó no siempre favoreció a los varones ni significó un perjuicio absoluto para las mujeres.

Por otro lado, a través de los dos casos analizados, pudimos constatar que, tanto Ana Joaquina Silva de Melo como María del Carmen Mármol, no necesariamente se manejaron habilitadas por sus respectivos cónyuges. En el caso de la primera, sin duda hubo operaciones comerciales en la que el esposo otorgó la mentada licencia, tal la concedida para el envío de una expedición al puerto de la Habana en 1787, o la que le permitió a la mujer la compra de la fragata "El Tártaro". Pero, también resultaba del discurso de Melo que su mujer "giraba con gruesas negociaciones suyas", que desde "que estaba casada siempre había tenido y girado su caudal por separado". Ello pareciera indicar que la mujer podía prescindir de la habilitación de su cónyuge para intervenir en los asuntos relacionados con el comercio, aunque, claro está, bien pudo haber sido ésta una estrategia de Melo a sabiendas de que su mujer estaba protegida por la ley.

En el caso de la segunda, la misma mujer hacía constar que debía relegar sus tareas mujeriles una vez al año, para dedicarse al traslado de los cueros y otras utilidades desde la estancia al embarcadero. Alegaba haber convenido en hacer contrato y haber realizado los suficientes viajes con su producción como para saber de los fletes y del regular precio de los mismos. 
Por otro lado, también despachaba su producción a Cádiz a su cuenta y riesgo, sin mediar para la operación habilitación alguna; de hecho, su esposo se hallaba ausente en los reinos de España, como ella misma lo dijera.

Desde la perspectiva femenina, la necesidad de apelar a la presencia masculina para acreditar un lugar en la sociedad no significó que la figura del varón como tal fuera imprescindible a la hora de tomar decisiones y desenvolverse en ausencia del marido.

Sin duda, la participación de estas mujeres fue tan activa como la de los varones en el proceso de construcción, transmisión y consolidación de la diferencia genérica, no obstante lo cual, no puede desconocerse su participación en actividades consideradas propias del hombre como era el comercio de ultramar. Así, las encontramos interviniendo en la exportación de utilidades o en negocios como la compra de una fragata o la realización de contratas comerciales, intereses todos estos relacionados con el ámbito portuario, lo que nos da la pauta de que, más allá de las concepciones ideológicas aceptadas por la sociedad colonial, éste no fue un espacio excluyente en función del sexo.

Asimismo, y a través de la articulación de los discursos masculino y femenino, hemos podido servirnos de una variable de análisis válida a la hora de identificar las estrategias y mecanismos de los que se sirvieron mujeres y hombres en la construcción de los roles.

Es evidente que la habilitación del cónyuge en función del vínculo matrimonial, como el aprovechamiento de su licencia y consentimiento, fueron las estrategias utilizadas por Ana Joaquina para involucrarse en cuanta actividad económica se presentaba. Sin duda, el empleo de las relaciones y conexiones generadas por Melo, así como las influencias de éste en función del cargo oficial que detentaba, le significaron la posibilidad de realizar transacciones como la compra de una fragata o la conformación de una sociedad comercial. Ello, por supuesto, sin quitarle mérito a los vínculos que supo granjearse por su cuenta doña Ana Joaquina ni al usufructo que hizo Melo de su relación conyugal.

El hecho es que, desde la perspectiva que ofrece el discurso masculino, los fundamentos esgrimidos por el imputado nos inducen a ver a Manuel Cipriano de Melo aparentemente como un sujeto pasivo; habilitador o no, su estrategia pudo haber pasado por endilgar a la mujer la decisión y ejecución en aquellos asuntos comerciales.

En el otro caso analizado, la estrategia de María del Carmen Mármol fue el aprovechamiento de su condición de mujer de esposo ausente y la 
connotación que ello suponía. Sin duda, las estrategias y mecanismos de los que se sirvió al desarrollar las actividades comerciales, que abarcaban todas las etapas de la producción según se desprende de su discurso, pasaban por hacer uso de la condición propia de su sexo conforme a la imagen que la sociedad colonial tenía de la mujer. El mismo demandado, y esto nos permite también observar cómo se han ido construyendo las diferencias genéricas, utilizaba en su defensa una de las características atribuidas a las mujeres: el apasionamiento, para desacreditar la acción impetrada por Mármol.

Si bien, por un lado, teniendo en cuenta el ámbito en que se desenvolvieron éstas mujeres, no ha podido identificarse una correspondencia directa entre la diferencia genérica y la que remite a la sexualidad, por el otro, ésta se hizo más nítida a partir de las estrategias adoptadas por las mujeres y los varones. Estrategias que se vinculaban, a su vez, a las opciones diferenciales que se les presentaban, en congruencia con la concepción femenina y masculina que asociaba a las mujeres con los valores domésticos y a los varones con el trabajo productivo, conforme a las concepciones ideológicas aceptadas por la sociedad colonial del siglo XVIII. 